\title{
Evaluation of the treatment efficacy of patients with multiple sclerosis using Barthel index and expanded disability status scale
}

\author{
Edina Tanovićc ${ }^{\star}$, Dževad Vrabac ${ }^{1}$, Aldijana Kadić1 ${ }^{\text {, Admir Rama², Haris Tanović }}$

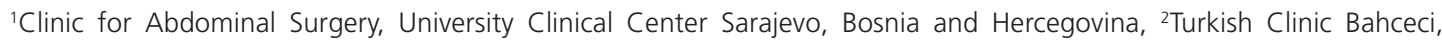 \\ Sarajevo, Bosnia and Hercegovina, ${ }^{3}$ Clinic for Physical Medicine and Rehabilitation, University Clinical Center Sarajevo, \\ Bosnia and Hercegovina
}

\begin{abstract}
Introduction: Multiple sclerosis (MS) is a chronic, autoimmune and progressive multifocal demyelinating disease of the central nervous system. The aim of this study was to evaluate rehabilitation of patients with multiple sclerosis using BI (Barthel index) and EDSS (Expanded Disability Status Scale).

Methods: A clinical observational study was made at the clinic for physical medicine and rehabilitation in Sarajevo. We analyzed 49 patients with MS in relation of gender, age and level of disability at admission and discharge, patient disability were estimated using EDSS scale. The ability of patients in their activities of daily living were also analyzed according to the BI at admission and discharge.
\end{abstract}

Results: Of the total number of patients $(n=49)$ there were 15 men and 34 women. The average age of female patient was $42.38 \pm 13.48$ and male patient $46.06 \pm 9.56$. EDSS values were significantly different at the beginning and at the end of the therapy $(p=0.001)$ as was the value of $B I(p=0.001)$.

Conclusion: MS patients, after the rehabilitation in hospital conditions show significant recovery and a reduced level of disability; they show higher independence in activities but rehabilitation demands individual approach and adjustment with what patients are currently capable of achieving.

Keywords: rehabilitation; MS (Multiple Sclerosis); EDSS (Expanded Disability Status Scale); BI (Barthel Index)

\section{INTRODUCTION}

Multiple sclerosis (MS) is a chronic, demyelinating and progressive multi-focal disease which affects

\footnotetext{
*Corresponding author: Prof. Dr Edina Tanović, Clinic for Physical medicine and rehabilitation, University Clinical Center Sarajevo,

Bolnička 25, 71000 Sarajevo,

Bosnia \& Herzegovina

E-mail: tanovicedina@hotmail.com
}

Submitted August 03, 2014 / Accepted September 08, 2014 the auto-immunity of the central nervous system. When a certain part of the myelin sheath is inflamed and damaged, transfer of impulses through neurons is disturbed, slow or intermittent (1-3). Clinical symptoms of MS include nystagmus, tremors and dysarthria, eye disorder, movement disorders, sensibility problems with the coordination and balance of movement, problems with urination and defecation, sexual dysfunction, disturbances in cognition, fatigue, pain etc. $(4,5)$. 
Symptomatic treatment includes a full range of procedures that aim to alleviate the existing symptoms, in order to maintain active mobility for as long as possible and reduce the degree of disability of these patients $(6,7)$.

The plan of rehabilitation of these patients is made to the status of disability by EDSS scale. The minimum value of the EDSS scale is 0 (normal neurological examination result) and the highest 10 (death due to complications of MS).

Activities of daily living were assessed by the Barthel Index with the lowest value of 0 (total dependence on others for care and assistance) to 20 (independent in activities of daily living) $(8,9)$.

MS is often diagnosed in people between the ages of 25 and 50, but rarely in children and persons above age of 60 . Women are 2 to 3 times more prone than man in contracting MS (6,7).

The aim of this study was to evaluate rehabilitation of patients with multiple sclerosis using BI (Barthel index) and EDSS (Expanded Disability Status Scale).

\section{METHODS}

A clinical observational study was made at the Clinic for physiology and rehabilitation, University Clinical center Sarajevo. The study included 49 patients with MS of both genders aged between 18 and 65 who were diagnosed with MS and who have undergone the recommended physical therapy as per the protocol. The study excluded patients who have not undergone physical therapy as per the protocol or had their treatment continued at the Neurological clinic in Sarajevo due to the worsening of the underlying disease. Level of disability of patients at admission and discharge in accordance with the EDSS (Expanded Disability Status Scale) is used as a measure of disease progression. This scale ranges from 0 to 10 , with lower scores indicating lower level of disability. We have also analyzed the abilities of the patients in their activities of daily living according to the Barthel index at admission and discharge. This scale ranges from 0 to 20 . A patient is fully dependent when the sum of point was 0-4, 5-12 shows high level of dependence, 13-18 shows moderate level, 19 shows low level and 20 shows total independence.

\section{Statistical analysis}

All the analytical data are presented in tables with an absolute number of cases, the arithmetic mean, standard deviation and range of value $\chi^{2}$ - square test. We also used ANOVA and Wilcoxon nonparametric test. All the tests with $\mathrm{p}<0.05$ were considered statistically significant.

\section{RESULTS}

Of the total number of patients $(n=49)$ there were 15 men and 34 women. The average age was $43.51 \pm 12.43$, the average age of female patients was $42.38 \pm 13.48$ years, and the average age of male patients was $46.06 \pm 9.56$ years (Table 1 ).

By using a nonparametric Wilcoxon test, there was a statistically significant difference in the EDSS value before and after therapy (Table 2). The EDSS value before therapy was $6.04 \pm 1.52$ (required regular or occasional assistance to walk up to $100 \mathrm{~m}$ with or without rest), whereas after therapy, the value fell to $5.46 \pm 1.51$ (mobile without aid or rest, but with restrictions in daily activities), $\mathrm{Z}=-0.514 ; \mathrm{p}=0.001$.

By analyzing activities of daily living of the patients-before and after the therapy-based on the Barthel index and by implementing the Wilcoxon test, we have established a statistically significant difference in the clinical status. Before the therapy and after reception, based on the Barthel index, the patients were classified in the heavily dependent category $(12.89 \pm 5.52)$, while after therapy their clinical

TABLE 1. Gender and age of patients

\begin{tabular}{lcccccccc}
\hline & $\mathrm{N}$ & Mean & SD & SE & \multicolumn{2}{c}{$95 \% \mathrm{Cl}$ for mean } & Minimum & Maximum \\
\cline { 6 - 7 } & & & & & Lower bound & Upper bound & & \\
\hline Female & 34 & 42.38 & 13.48 & 2.31 & 37.67 & 47.08 & 18.00 & 66.00 \\
Male & 15 & 46.06 & 9.56 & 2.46 & 40.76 & 51.36 & 28.00 & 65.00 \\
Total & 49 & 43.51 & 12.43 & 1.77 & 39.98 & 47.08 & 18.00 & 66.00 \\
\hline
\end{tabular}


condition improved and they were classified, according to the Barthel index, with moderate dependence (14.48 5.37), $\mathrm{Z}=-4.843 ; \mathrm{p}=0.001$ (Table 3).

\section{DISCUSSION}

Multiple sclerosis (MS) is a chronic disease of the central nervous system. It was named after lesions where histopathological samples of brain tissue appear as indurated areas-plaques (6). These plaques are "disseminated" in different areas of the central nervous system and appear at irregular intervals. With the development of neuro-radiological techniques, especially MRI (magnetic resonance imaging) of the brain, the number of diagnosed and newly diagnosed patients with MS has dramatically increased. It was found that in patients with MS, typically only one clinical manifestation of the disease occurs for each new 8 to 10 new lesions in the brain, that were confirmed by MRI (7).

Clinical features of patients with MS is actually very diverse with different symptoms that vary in severity. These patients, after diagnosis and neurological therapy, register for the rehabilitation mainly because of the problems with their motor skills and their inability to control their sphincters $(8,9)$.

Study results show statistically significant difference in the gender representation of the respondents, and in the examined sample women dominated $(p=0.007)$. These figures correspond to data from the literature; female patients suffer from MS, 2 to 3 times more than men.

TABLE 2. EDSS scale values at admission and discharge

\begin{tabular}{lccccc}
\hline & $\mathrm{N}$ & Mean & Std. deviation & Minimum & Maximum \\
\hline $\begin{array}{l}\text { EDSS at } \\
\text { admission }\end{array}$ & 49 & 6.0408 & 1.52697 & 3.00 & 9.00 \\
$\begin{array}{l}\text { EDSS at } \\
\text { discharge }\end{array}$ & 49 & 5.4694 & 1.51523 & 3.00 & 9.00 \\
\hline
\end{tabular}

$Z=-0.514 ; p=0.001$

TABLE 3. Barthel index value at admission and discharge

\begin{tabular}{lccccc}
\hline & $\mathrm{N}$ & Mean & Std. deviation & Minimum & Maximum \\
\hline $\begin{array}{l}\text { Bl at } \\
\text { admission }\end{array}$ & 49 & 12.89 & 5.52 & 3.00 & 20.00 \\
$\begin{array}{l}\text { Bl at } \\
\text { discharge }\end{array}$ & 49 & 14.48 & 5.37 & 4.00 & 20.00 \\
\hline
\end{tabular}

$\mathrm{Z}=-4.834 ; \mathrm{p}=0.001$
Analysis of the age structure of patients shows that the average age was $43.51 \pm 12.43$, the average age of female patients was $42.38 \pm 13.48$ years, and for male patients, it was $46.06 \pm 9.56$ years. This data indicates that there is no statistically significant difference in age structure of the respondents in relation to their gender $(p=0.344)$. Research conducted earlier show that the average age of patients with MS in rehabilitation was lower. We think that reason for this difference is better diagnosis and the earlier involvement of patients in the rehabilitation process, but it is also possible that other studies involved younger patients $(10,11)$.

The assessment of the degree of disability is shown through EDSS and used as a measure of the progression of the disease and severity of neurological disorder in these patients (12). During the process of rehabilitation, patients tried to increase their mobility by kinesiotherapy (13). Also, all patients underwent occupational therapy to gain competence in day to day activities. The analysis of the EDSS values before and after the therapy showed statistically significant differences. The EDSS value before therapy was V6.04 \pm 1.52 which means that patients needed permanent or temporary orthopedic aid such as the use of canes, crutches or walking frame to walk up to $100 \mathrm{~m}$, with or without rest; while after the therapy, the value dropped to $5.46 \pm 1.51$, which means that the patient is mobile without assistance or rest, but is limited in daily activities $(p=0.001)$. Our research shows that patients with a greater degree of disability were registered for the rehabilitation then what other studies have shown $(14,15)$. Research conducted in France and England have shown that inpatient rehabilitations is carried out for small disabilities and in the earlier phases of the disease when they expect the effects of the treatment to be better (16-18).

By analyzing the activities of daily living according to the Barthel index, significant statistical difference in clinical conditions was established $(\mathrm{p}=0.001)$ before and after physical therapy. Upon reception, the patients were classified as being heavily dependent $(12.89 \pm 5.52)$, while after the treatment, their clinical condition improved and they were, according to the Barthel index, classified as being moderately dependent $(14.48 \pm 5.37)$. These 
data confirm that physical therapy (kinesiotherapy and occupational therapy) is of great importance in enabling patients in carrying out day to day activities. Research done in the last three years also gives similar results. It is recommended that the evaluation of different possibilities and aspects of physical therapy should be tailored to each patient and to respect current possibilities of these patients in each therapeutic procedure (19,20). An important prognostic factor is the movement in the Barthel index at the beginning, during and after physical therapy which will, if stagnant, show that the best clinical recovery in day to day life activities has been reached (20).

\section{CONCLUSION}

Patients with the MS, after rehabilitation in hospital conditions, show significant recovery and reduced degrees of disability. In activities of daily living they were more independent, but the rehabilitation demands an individual approach and adaptation to the current capacities of the patients.

\section{CONFLICT OF INTEREST}

The authors declare no conflict of interest.

\section{REFERENCES}

1. Tešija KA, Topić E, Primorac D, Janković S. Medicinsko biokemijska dijagnostika u kliničkoj praksi. Autoimunosne bolesti. Zagreb: Medicinska naklada 2004;288-303.

2. Rosati G. The prevalance of multiple sclerosis in the world an update. Neuro Sci 2001;22(2):117-39. http://dx.doi.org/10.1007/s100720170011.

3. Alonso A, Hernan MA. Temporal trends im the imcidence of multiple sclerosis: a systematic review. Neurology 2008;71(2)129-35. http://dx.doi. org/10.1212/01.wnl.0000316802.35974.34.

4. Gilden MH. Infectious causes of multiple sclerosi. The Lancet Neurology 2005;4(3):195-202.http://dx.doi.org/10.1016/S1474-4422
(05)01017-3.5. Christensen T. The role of EBV in MS pathogenesis. INT MSJ 2006; 13(2): 52-7.

6. Rovira A, Swanton J, Tintoré M, Huerga E, Barkhof F, Filippi M, Frederiksen JL, Langkilde $A$, et all. A single, early magnetic resonance imaging study in the diagnosis of multiple sclerosis. Arch Neurol. 2009;66(5):587-92. http://dx.doi.org/10.1001/archneurol.2009.49.

7. Okuda DT, Mowry EM, Beheshtian A, Waubant E, Baranzini SE, Goodin DS, et all. Incidental MRI anomalies suggestive of multiple sclerosis: the radiologically isolated syndrome. Neurology. 2009;72(9):800-5. http://dx.doi.org/10.1212/01.wnl.0000335764.14513.1a.

8. Amarenco G, Denys P. Urinary disorders in multiple sclerosis: Algorythm and guidelines, the FLUE-MS. Europ $\mathrm{J}$ of Phys and Rehabil Med 2014;50(1) 110.

9. Denys P, Even A, Phe V, Chartier-Kastler E. Therapeutic management of urinary disorders in MS. Europ J of Phys and Rehabil Med 2014;50(1) 111

10. Previnaire JG, Lecort G, Soler JM. Sexual disorders in multiple sclerosis: evaluation and management. Europ $\mathrm{J}$ of Phys and Rehabil Med 2014;50(1) 110.

11. Lacoste-Guinet A, Verollet D, Le Breton F, Peyrat L, Amarenco G. Prevalence of stress urinary incontinence in women with multiple sclerosis. Europ J of Phys and Rehabil Med 2014;50(1) 111.

12. Pelletier J, Rico A, Adoin B. Multiple Scerosis treatment options: Update 2014 Europ J of Phys and Rehabil Med 2014;50(1) 111.

13. Robinet E, Favre A, Zaaraoui W, Guye M, Asquinazi P, Bardot P, Pelletier J, Ranjeva JP, Audoin B. Physical rehabilitation in associated with structural and functional brain plasticity in patients with multiple sclerosis. Europ $\mathrm{J}$ of Phys and Rehabil Med 2014;50(1) 111.

14. Gallien P, Nicolas B, Durufle A, Robineau S, Petrilli S, Autret K, Houdakor J, Le Meur $\mathrm{C}$. Physical training and muscle strengthening im multiple sclerosis. Europ J of Phys and Rehabil Med 2014;50(1) 112.

15. Thoumie P. Balance in multiple sclerosis. Evaluation and rehabilitation. Europ J of Phys and Rehabil Med 2014;50(1) 112.

16. Allart E, Benoit A, Thevenon A, Tiffreau V, Outteryck O, Zephir H, Lacour A, Vermersch $P$, Blanchard $A$. Characteristics of walking fatigability in Mutiple Sclerosis. Europ J of Phys and Rehabil Med 2014;50(1) 112-3.

17. Rasova K. Describing availability and characteristics of ohysical therapy in Multiple Sclerosis across Europe: a qualitative study. Europ J of Phys and Rehabil Med 2014;50(1) 115.

18. Loiseau K, Valentini F, Robain G. Management of urinary dysfunction in multiple sclerosis patients: our experience vs United-Kingdom consensus. J Neurol Neurosurg Psychiatry 2009;80:470-477.

19. Norbert M, Lemaire-Desreumaux S, Guyot MA, Donze C, Weissland T. Contribution of the adapted physical activities for the improvement of the quality of life at the persons affected by multiple sclerosis. American Journal od Prevetive Medicine 2013;44:76-84.

20. Layadi K, Chu O. Multiple sclerosis, a multidimensional disability. Europ J of Phys and Rehabil Med 2014;50(1) 117. 